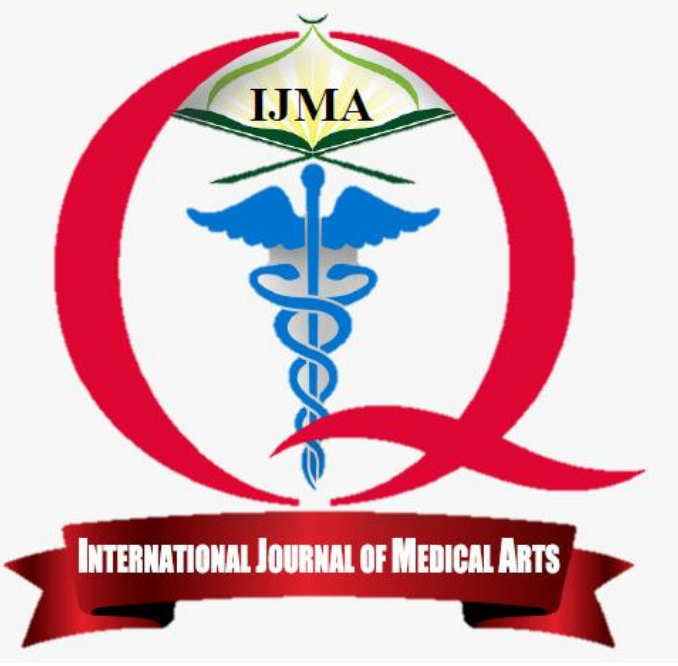

Available online at Journal Website

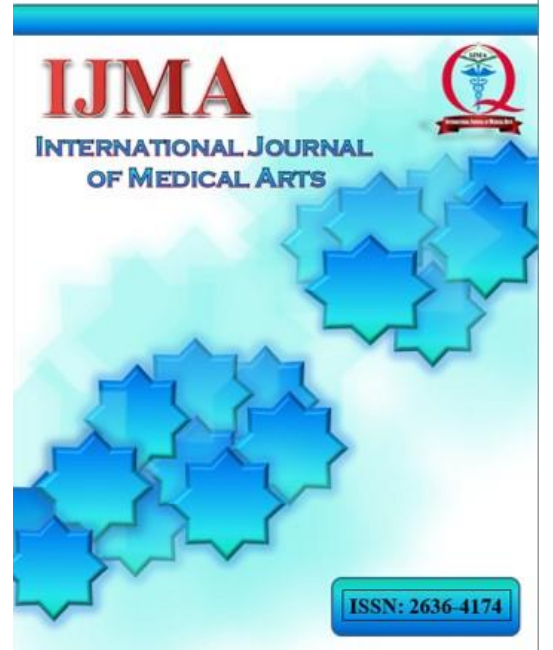

Original article

\title{
Effect of Lactoferrin Supplementation on Iron Deficiency Anemia in Primary School Children
}

\author{
Abeer Hassan El-Khawaga, Hussein Metwally Abdelmaksoud
}

Pediatric Department, Damietta Faculty of Medicine, Al-Azhar University, Egypt.

\section{Corresponding author}

\section{Abeer Hassan El-Khawaga \\ Pediatric Department; Damietta}

Faculty of Medicine, Al-Azhar University, Egypt

Email: drabeerhassan3683@gmail.com

Received at: May 7, 2019.

Revised at: June 7, 2019

Accepted at: June 7, 2019.

Available online: June 8, 2019
Background: Many studies were done to evaluate the effect of oral lactoferrin administration on iron deficiency anemia, with controversial results.

Objective: This study was designed to assess the effects of lactoferrin supplementation on primary school children having iron deficiency anemia.

Patients and Methods: Prospective cohort study was conducted on 94 patients with iron deficiency anemia. They were 58 females and 36 males. Their ages range from 6 years to 12 years with mean age of 8.4 years. In the period between October 2018 and January 2019. Each child was submitted to full history taking, complete clinical examination and laboratory investigations including complete blood count, Serum ferritin, serum iron and total iron binding capacity.

Results: Oral administration of bovine lactoferrin (BLf) significantly increases the number of red blood cells, hemoglobin, serum ferritin and total iron after thirty days of the treatment. BLf is a more effective and safe alternative than elemental iron for treating iron deficiency and iron deficiency anemia.

Conclusions: Lactoferrin is a better substitute for elementary iron in treatment of iron deficiency.

Keywords: Iron; Anemia; Iron Deficiency; Primary school Children.

\section{https://doi.org/10.21608/ijma.2019.12596.1003}

This is an open access article under the Creative Commons license (CC BY) (https://creativecommons.org/licenses/by/2.0/)

Please cite this article as: El-Khawaga AH, Abdelmaksoud HM. Effect of Lactoferrin Supplementation on Iron Deficiency Anemia in Primary School Children. IJMA 2019; 1 (1): 48. Article in Press, https://doi.org/10.21608/ijma.2019.12596.1003. 


\section{Introduction}

Iron deficiency (ID) anemia (IDA) is a challenging health problem in pediatrics. It is the most common nutritional deficiency all-over the world, mainly in developing countries. World health organization (WHO) in 2001 estimated that $30 \%$ of children aged 0-4 years and $48 \%$ of children aged 514 years were anemic. The etiologies of iron deficiency in children include inadequate iron intake and increased needs due to rapid growth ${ }^{[1]}$. ID and IDA had a remarkable adverse effect on children health. Negative effects include - but not limited to - stunted development, low immunity, decrease IQ values, reduced capacity of physical activity, increased fatigue, poor psychomotor, cognitive power and school achievement ${ }^{[2]}$.

Children with mild IDA were usually asymptomatic. However, some of them could be presented with pica, easy fatigability, irritability, palpitation, shortness of breath, conjunctival pallor and/or pallor of palms and nail bed. In children with severe iron deficiency anemia; tachycardia and heart failure may be developed ${ }^{[3]}$. The most commonly used definitions of anemia are from the Centers for Disease Control and Prevention (CDC) and the World Health Organization (WHO), based on hemoglobin levels (levels $<11 \mathrm{~g} / \mathrm{dl}$ in infants aged 0.5-5 years: and $<11.5 \mathrm{~g} / \mathrm{dl}$ in children aged 5-12 years. Prevention of iron deficiency anemia is an important public health issue and many strategies are available (e.g. iron supplementation, fortification of foods, proper management of parasitic infestation and dietary diversification $)^{[4]}$.

Recently, some researcher suggested that, lactoferrin could play a role in solving this global health issue ${ }^{[5]}$. Lactoferrin is an iron binding, nonhaem protein that is structurally and chemically similar to serum transferrin, the transporter of iron in the serum. It is produced by epithelial cells of mucosa and found in secretions as saliva, tears, nasal, bronchial secretions and abundantly secreted in milk ${ }^{[6]}$. Lactoferrin has proved to have 300 times higher affinity to iron as compared to serum transferrin and an ability to retain iron over a broader $\mathrm{PH}$ range. Also, it was evidenced that it affects iron homeostasis by increasing iron export from gastrointestinal tract (GIT) and enhancing iron storage in ferritin. These mechanisms have proved to give better results with patients who are using lactoferrin as compared with those using ferrous sulphate in terms of red cell count, hemoglobin level, serum ferritin and total serum iron ${ }^{[7]}$.

\section{Aim of the study}

This study was designed to assess the effects of oral lactoferrin administration on primary school children having iron deficiency anemia.

\section{Patients and Methods}

The current work was designed as a prospective cohort study and was conducted on 94 patients with IDA. They were 58 females and 36 males. Their ages range from 6 to 12 years with mean age of 8.4 years. This study was performed in the period between October 2018 and January 2019. Children of this study has been collected from two different primary schools in Tanta City. Letters from Pediatric Department (Al-Azhar Faculty of Medicine, Damietta) to primary schools for cooperation in this study. In our study, children were studied to evaluate the effect of oral Lf on treating IDA instead of elemental iron. They were numbered randomly from 1 to 94 (There were nine children not responding to follow up). They were classified into: Group 1: (included children with odd numbers) 47 children received lactoferrin as a treatment of anemia. Oral bovine lactoferrin (one sachet contains $100 \mathrm{mg}$ of bovine lactoferrin over a quarter cup of water) was given twice daily for one month before meals. Group 2: (included children with even numbers) 47 children received iron as treatment of anemia. Elemental iron $(6 \mathrm{mgl} / \mathrm{kg} / \mathrm{day})$ was administered orally with meals, once daily for 30 days.

Inclusion criteria: the study included children of primary school age with iron deficiency anemia and both sexes were involved. Exclusion criteria: children with one or more of the following: chronic infections as TB, collagen diseases, renal diseases, liver diseases, malignancies and those underwent iron therapy or received blood transfusion in the last 3 months, were excluded. For all children, full history and clinical examinations were carried out. Also, blood samples were collected to measure ferritin and iron in serum, total iron binding capacity, and to do complete blood count, at baseline (Just before initiation of treatment) and after one month; after regular therapy by bovine lactoferrin or elemental iron.

Statistical analysis: Data were collected, coded, revised and analyzed by the Statistical Package for Social Science (IBM® ${ }^{\circledR}$ SPSS ${ }^{\circledR}$, Chicago, USA) version 20. Frequency and percent were calculated for the qualitative data, while mean, standard deviations and ranges were calculated for the quantitative data with parametric distribution and median with inter quartile range (IQR) for non- 
parametrically distributed data. The p-value $<0.05$ was considered significant.

\section{Results}

In the present study, males represented $41.2 \%$ and females $58.8 \%$ of studied children. The mean age was $8.40 \pm 1.90$ years. The socioeconomic state was high in $14.1 \%$, moderate in $42.4 \%$, low in $27.1 \%$ and very low in $16.5 \%$. General examination revealed that, no patients had jaundice, while 5.9\% had severe pallor and $91.8 \%$ had some pallor. The mean weigh was $28.02 \pm 9.62 \mathrm{~kg}$, while mean height was $124.49 \pm 13.22 \mathrm{~cm}$; no patients had lymphadenopathy, hepatomegaly or splenomegaly. However, $20.0 \%$ of studied children had tachycardia (table 1).

In the present work, there was statistically significant increase of hemoglobin, RBCs, MCHC, serum ferritin and serum iron after treatment in lactoferrin group when compared to elemental iron group (table 2).

Table (1): General characters, general and systemic examinations among studied children

\begin{tabular}{|c|c|c|c|c|}
\hline & & No. & $\%$ \\
\hline & \multicolumn{2}{|c|}{ Female } & 50 & $58.8 \%$ \\
\hline Sex & \multicolumn{2}{|c|}{ Male } & 35 & $41.2 \%$ \\
\hline Age & \multicolumn{2}{|c|}{ Mean \pm SD } & \multicolumn{2}{|c|}{$8.40 \pm 1.90$} \\
\hline \multirow{4}{*}{ Socio-economic Status } & \multicolumn{2}{|l|}{ High } & 12 & $14.1 \%$ \\
\hline & \multicolumn{2}{|c|}{ Moderate } & 36 & $42.4 \%$ \\
\hline & \multicolumn{2}{|l|}{ Low } & 23 & $27.1 \%$ \\
\hline & \multicolumn{2}{|c|}{ Very low } & 14 & $16.5 \%$ \\
\hline \multirow{5}{*}{ General examination } & \multirow{2}{*}{ Pallor } & Severe & 5 & $5.9 \%$ \\
\hline & & Some & 78 & $91.8 \%$ \\
\hline & \multicolumn{2}{|c|}{ Jaundice } & 0 & $0.0 \%$ \\
\hline & \multicolumn{2}{|c|}{ Weight (mean $\pm S D$ ) } & \multicolumn{2}{|c|}{$28.02 \pm 9.62$} \\
\hline & \multicolumn{2}{|c|}{ Height (mean $\pm S D)$} & \multicolumn{2}{|c|}{$124.49 \pm 13.22$} \\
\hline \multirow{4}{*}{ Systemic examination } & \multicolumn{2}{|c|}{ Lymphadenopathy } & 0 & $0.0 \%$ \\
\hline & \multicolumn{2}{|c|}{ Tachycardia } & 17 & $20.0 \%$ \\
\hline & \multicolumn{2}{|c|}{ Hepatomegaly } & 0 & $0.0 \%$ \\
\hline & \multicolumn{2}{|c|}{ Splenomegaly } & 0 & $0.0 \%$ \\
\hline
\end{tabular}

Table (2): Comparison between lactoferrin and elemental iron groups regarding laboratory investigation

\begin{tabular}{|c|c|c|c|c|c|c|c|}
\hline & \multicolumn{2}{|c|}{$\begin{array}{c}\text { Lactoferrin group } \\
\text { (No.=43) }\end{array}$} & \multicolumn{2}{|c|}{$\begin{array}{c}\text { Elemental iron group } \\
(\text { No. }=42)\end{array}$} & \multirow{2}{*}{$\begin{array}{c}\text { Mean } \\
\text { Difference }\end{array}$} & \multirow{2}{*}{$p$ value } \\
\hline & & Mean & SD & Mean & SD & & \\
\hline \multirow{2}{*}{$\begin{array}{l}\text { Hemoglobin } \\
(\mathrm{g} / \mathrm{dl})\end{array}$} & Before treatment & 9.7 & 0.49 & 9.6 & 0.66 & 0.1 & 0.429 \\
\hline & After treatment & 10.84 & 0.59 & 10.2 & 0.70 & 0.64 & $0.001^{*}$ \\
\hline \multirow[t]{2}{*}{ RBCs (m/cmm) } & \begin{tabular}{|l} 
Before treatment \\
\end{tabular} & 3.91 & 0.31 & 3.71 & 0.29 & 0.2 & $0.003^{*}$ \\
\hline & After treatment & 4.40 & 0.34 & 4.15 & 0.31 & 0.25 & $0.001^{*}$ \\
\hline \multirow[t]{2}{*}{ Hematocrit \% } & \begin{tabular}{|l} 
Before treatment \\
\end{tabular} & 30.02 & 2.11 & 29.7 & 2.3 & 0.32 & 0.50 \\
\hline & After treatment & 30.7 & 2.06 & 30.1 & 1.81 & 0.6 & 0.157 \\
\hline \multirow[t]{2}{*}{ MCV (fl) } & \begin{tabular}{|l|} 
Before treatment \\
\end{tabular} & 73.6 & 4.05 & 72.3 & 4.5 & 1.3 & 0.165 \\
\hline & After treatment & 76.8 & 3.9 & 76.2 & 4.1 & 0.6 & 0.491 \\
\hline \multirow[t]{2}{*}{$\mathrm{MCH}(\mathrm{pg})$} & Before treatment & 24.5 & 1.7 & 24.7 & 1.7 & 0.2 & 0.589 \\
\hline & After treatment & 27.2 & 1.8 & 26.4 & 2.3 & 0.8 & 0.077 \\
\hline \multirow[t]{2}{*}{$\mathrm{MCHC}(\mathrm{g} \%)$} & \begin{tabular}{|l|} 
Before treatment \\
\end{tabular} & 33.4 & 1.20 & 32.9 & 1.4 & 0.5 & 0.082 \\
\hline & After treatment & 35.8 & 2.2 & 34.1 & 1.7 & 1.7 & $0.001^{*}$ \\
\hline \multirow[t]{2}{*}{ Serum ferritin } & \begin{tabular}{|l|} 
Before treatment \\
\end{tabular} & 14.9 & 7.46 & 16.6 & 7.4 & 1.7 & 0.294 \\
\hline & After treatment & 40.3 & 18.3 & 24.8 & 9.4 & 15.5 & $0.001^{*}$ \\
\hline \multirow[t]{2}{*}{ Serum iron } & Before treatment & 39.2 & 8.8 & 41.9 & 8.9 & 2.7 & 0.163 \\
\hline & After treatment & 69.6 & 14.3 & 63.0 & 14.7 & 6.6 & $0.038^{*}$ \\
\hline \multirow[t]{2}{*}{ TIBC } & Before treatment & 3.9 & 0.42 & 3.8 & 0.47 & 0.1 & 0.303 \\
\hline & After treatment & 3.16 & 0.46 & 3.2 & 0.47 & 0.04 & 0.692 \\
\hline
\end{tabular}

RBCs: Red blood cells; MCV: mean cell volume; MCH: mean cell hemoglobin; MCHC: mean cell hemoglobin concentrations; TIBC: total iron binding capacity.

\section{Discussion}

This study was designed to assess the effects of Lf supplementation for primary school children with IDA. Lactoferrin is structurally and chemically comparable to serum transferrin (functions as iron transporter in the serum $)^{[7]}$. Lf has 300 times higher affinity to iron than serum transferrin and an ability to retain iron over a broad $\mathrm{PH}$ range ${ }^{[8]}$. Monitoring of complete blood picture (CBC) and iron profile including serum iron, serum ferritin and total iron binding capacity (TIBC) before and after one month 
of treatment. These mechanisms have proved to give better results with patients who are using $\mathrm{Lf}$ as compared with those using elemental iron in terms of red cell count, hemoglobin level, serum ferritin and total serum iron ${ }^{[9]}$.

Regarding clinical presentation, pallor detected in about $97 \%$ of cases. This agree with the study conducted by Ali et al. ${ }^{[10]}$ that found that pallor was the most common sign observed in iron deficient children..

In terms of laboratory investigations, the current study noted that at the beginning of the study, both groups were comparable as regard to hemoglobin concentration. However, after one month of treatment, both groups showed significant increase of hemoglobin with significant increase in lactoferrin group. This agreed with the study of Rezk et al. ${ }^{[11]}$ that stated that mean increase of hemoglobin level was by $(2.26 \pm .51 \mathrm{~g} / \mathrm{dl})$ in patients with IDA who received Lf for 8 weeks on a dose of $250 \mathrm{mg}$ once daily. Another study by Paesano et al. ${ }^{[9]}$ revealed that mean increase of hemoglobin level was $(1.7 \pm 0.9$ $\mathrm{g} / \mathrm{dl}$ ) in patients with IDA who received Lf for 30 days on a dose of $100 \mathrm{mg}$ twice daily.

The mean hematocrit count was $30.02 \%$ and increase to $30.7 \%$ in Lf group and mean value was $29.7 \%$ before treatment, increased to $30.1 \%$ in elemental iron group. This agreed with the study of King et al. ${ }^{[12]}$, who carried out a pilot study of Lf supplementation for infants and revealed that supplementation Lf had potentially favorable outcomes such as marked reduction of lower respiratory tract infection and increased hematocrits.

Mean serum ferritin before treatment was 14.98 $\mathrm{ng} / \mathrm{ml}$ and after 1 month it increased to $40.30 \mathrm{ng} / \mathrm{ml}$ in Lf group, while in elemental iron group, it was $16.95 \mathrm{ng} / \mathrm{ml}$ before treatment and after one month, increase to $24.80 \mathrm{ng} / \mathrm{ml}$. This agreed with the study of the serum ferritin level noted by Paesano et al. ${ }^{[9]}$, in which ferritin was $\leq 12 \mathrm{ng} / \mathrm{ml}$ initially while after one month of treatment it was $29 \pm 7 \mathrm{ng} / \mathrm{ml}$.

Mean total serum iron before treatment was $39.2 \mathrm{mg} / \mathrm{dl}$ and after 1 month it increases to 69.6 $\mathrm{mg} / \mathrm{dl}$ in Lf group compared to $41.9 \mathrm{mg} / \mathrm{dl}$ and 63.0 $\mathrm{mg} / \mathrm{dl}$ before and after one month of treatment in elemental iron group. This consisted with the study of Paesano et al. ${ }^{[13]}$, who study Lf versus iron (ferrous sulphate) in management of iron deficiency and IDA and reported that, mean iron level before treatment was $\leq 30 \mathrm{mg} / \mathrm{dl}$, that elevated to $84 \pm 16 \mathrm{mg} / \mathrm{dl}$ after treatment for 30 days. Also, results coincides with the study of Ke et al.$^{[14]}$ who reported significant increase in iron absorption in exclusively breastfed infants after supplementation with Lf-fortified milk. Also, results in agreement with the study held by Bethell and Huang ${ }^{[15]}$.

Mean TIBC before treatment was 3.9 and after one month, it decreases to 3.1 in Lf group compared to, 3.8 before and 3.2 after treatment in elemental iron group. This agreed with the study of Rezk et al. ${ }^{[11]}$ that stated that of TIBC levels decreased in cases with IDA who received Lf for 8 weeks on a dose of 250 mg once daily.

In conclusion, oral lactoferrin represents a substitute for oral iron in the management of iron deficiency in children.

\section{References}

1. Özdemir N. Iron deficiency anemia from diagnosis to treatment in children. Turkish Arch Pediatr 2015; 50(1): 11-17.

2. Ullah I, Zahid M, Sthanadar AA, Sthanadar IA, Ali PA, Khan MI, et al. Iron Deficiency Anemia in School Age Children in District Karak Khyber Pakhtunkhwa Province, Pakistan. Open J Blood Dis 2014; 4(2): 9-15.

3. Janus J, Moerschel SK. Evaluation of anemia in children. Am Fam physician 2010; 81(12): 1462-1471.

4. Abu-Ouf NM, Jan MM. The impact of maternal iron deficiency and iron deficiency anemia on child's health. Saudi Med J 2015; 36(2): 146156.

5. Anand N, Kanwar RK, Mohan Lal Dubey R, Sehgal R, Verma AK, Kanwar JR. Effect of lactoferrin protein on red blood cells and macrophages: mechanism of parasite-host interaction. Drug Design Develop Ther 2015; 9: 3821-3831.

6. Jiang R, Lönnerdal $\mathbf{B}$ Cloning and characterization of the human lactoferrin receptor gene promoter." BioMetals 2018; 41 (5): 1-12.

7. Rosa L, Cutone A, Lepanto M, Paesano R, Valenti P. Lactoferrin: a natural glycoprotein involved in iron and inflammatory homeostasis. Int J Mol Sci 2017; 18(9): 1985-198

8. Cutone A, Frioni A, Berlutti F, Valenti P, Musci G, Di Patti MC. Lactoferrin prevents LPS-induced decrease of the iron exporter ferroportin in human monocytes/ macrophages. Biometals 2014; 27(5): 807-813. 
9. Paesano R, Berlutti F, Pietropaoli M, Pantanella F, Pacifici E, Goolsbee W, Valenti P. "Lactoferrin efficacy versus ferrous sulfate in curing iron deficiency and iron deficiency anemia in pregnant women." Biometals 2010; 23(3): 411-417.

10. Ali A, Fathy GA, Fathy HA, Abd El-Ghaffar N. Epidemiology of iron deficiency anemia: effect on physical growth in primary school children, the importance of hookworms. Int $\mathbf{J}$ Academic Res 2011; 3(1):8-33.

11. Rezk M, Dawood R, Abo-Elnasr M, Al Halaby A, Marawan H. Lactoferrin versus ferrous sulphate for the treatment of iron deficiency anemia during pregnancy: a randomized clinical trial. J Matern Fetal Neonatal Med. 2016;29(9):1387-90.

12. King Jr, JC, Cummings GE, Guo N, Trivedi L, Readmond BX, Keane V, Feigelman S, de Waard R. A double-blind, placebocontrolled, pilot study of bovine lactoferrin supplementation in bottle-fed infants. J Pediatr Gastroenterol Nutr 2007; 44(2): 245251.

13. Paesano R, Pacifici E, Benedetti S. Safety and efficacy of lactoferrin versus ferrous sulphate in curing iron deficiency and iron deficiency anaemia in hereditary thrombophilia pregnant women: an interventional study. Biometals 2014; 27(5): 999-1006.

14. Ke C, Lan Z, Hua L, Ying Z, Humina X, Jia $\mathbf{S}$, Weizheng $\mathbf{T}$, et al. Iron metabolism in infants: influence of bovine lactoferrin from iron-fortified formula. Nutrition 2015; 31(2): 304-309.

15. Bethell DR, Huang J. Recombinant human lactoferrin treatment for global health issues: iron deficiency and acute diarrhea. Biometals 2004; 17(3): 337-342. 